\section{Cil primaire et développement cérébral}

Nathalie Spassky, Andrea Aguilar
Inserm U711, Batiment Pharmacie, $5^{\mathrm{e}}$ étage, Hôpital Pitié-Salpêtrière, 47 boulevard de l'Hôpital, 75013 Paris, France. nathalie.spassky@upmc.fr
$>$ Les cellules souches neurales sont des cellules indifférenciées que l'on trouve dans le cerveau tout au long de la vie. Elles se caractérisent par leur capacité d'autorenouvellement et par leur multipotence (elles sont capables de se différencier en neurones et en cellules gliales). Elles sont localisées à proximité des ventricules cérébraux, elles sont de type astroglial (glie radiaire chez l'embryon et astrocyte chez l'adulte) et elles émettent un cil primaire $[1,12]$. La découverte récente de ces cellules a provoqué un grand enthousiasme dans le monde médical. D'une part, les cellules souches représentent un espoir pour le traitement des maladies neurodégénératives; d'autre part, leur dysfonctionnement pourrait être associé à la survenue de certaines tumeurs cérébrales [2, 14]. II est donc crucial de mieux comprendre les facteurs qui contrôlent leur prolifération et leur différenciation.

Le cil primaire, antenne des cellules de Vertébrés

Le cil primaire est une antenne présente à la surface de la plupart des cellules de Vertébrés. Elle s'étend à partir du centriole père de la cellule et possède un axonème de type $《 9+0 »$ (composé de neuf paires de microtubules périphériques sans doublet central). C'est une structure dynamique qui se forme et se résorbe au cours du cycle cellulaire grâce au transport intraflagellaire. En effet, des cargos moléculaires (dont des microtubules) sont véhiculés le long de l'axonème par des protéines motrices telles que la kinésine 2 et la dynéine qui sont indispensables à la formation et au maintien du cil. Ce cil concentre de nombreux récepteurs capables de détecter les messagers biochimiques présents dans le milieu extracellulaire. En particulier, les effecteurs de la voie Sonic Hedgehog (Shh) tels que les récepteurs Smoothened (Smo) et Patched, le facteur Suppressor of fused et les facteurs de transcription Gli ont tous été localisés dans le cil primaire [3].

L'absence de cil ou son dysfonctionnement sont à l'origine de nombreuses maladies graves appelées ciliopathies (polykystoses rénales, syndromes d'Alström, de Bardet-Biedl [13], de Joubert, de Meckel-Gruber et Oralfacial-digital-I) [4]. Ces pathologies sont fréquemment associées à des atteintes cérébrales comme le dérèglement du comportement alimentaire, le retard mental ou l'ataxie cérébelleuse. Cela suggère que le cil primaire est important pour le développement et le fonctionnement du cerveau [5]. $\varepsilon$ montrant que le morphogène Shh permet, grâce au cil primaire, l'expansion et la mise en place des cellules souches neurales, nous avons apporté la première preuve d'un rôle du cil primaire dans le développement du cerveau $[6,7]$.

Le cil primaire,

une structure clé pour l'amplification des progéniteurs granulaires

Les souris mutantes qui n'ont pas de cil primaire meurent très précocement (stade embryonnaire $\varepsilon 10$ ). Nous avons donc généré des souris mutantes condi- tionnelles chez lesquelles le cil primaire des progéniteurs granulaires est absent. Les souris mutantes utilisées sont issues d'un croisement entre (1) des souris exprimant la recombinase cre sous le contrôle du promoteur humain de la GFAP (glial fibrillary acidic protein), un gène spécifiquement exprimé dans les astrocytes et la glie radiaire, et (2) des souris porteuses d'allèles floxés du gène Kif3a, qui code pour une sous-unité de la kinésine 2, essentielle au développement ciliaire. En effet, les progéniteurs des neurones granulaires du gyrus dentelé de l'hippocampe et du cervelet, acquièrent leur identité à partir des cellules astrogliales hGFAP ${ }^{+}$du neuroépithélium embryonnaire. Ils migrent ensuite vers la zone sous-granulaire de I'hippocampe et la couche granulaire externe du cervelet où ils prolifèrent et donnent naissance à des neurones granulaires. Les souris mutantes hGFAP:: Cre; Kif3afl/fl meurent à trois semaines post-natales. Elles présentent une ataxie cérébelleuse et une hypotrophie du gyrus dentelé de l'hippocampe. Nous montrons que dans ces deux territoires, au cours du développement normal du cerveau, les progéniteurs des neurones granulaires émettent un cil primaire et prolifèrent activement en réponse à Shh. $\varepsilon n$ revanche, chez le mutant conditionnel, la prolifération des progéniteurs dépourvus de cil est dramatiquement réduite, et ceux-ci n'expriment plus certaines protéines comme le facteur de transcription Glil, dont l'expression traduit l'activation de la voie Shh. Ces résultats suggèrent donc que le cil primaire est nécessaire à la prolifération 


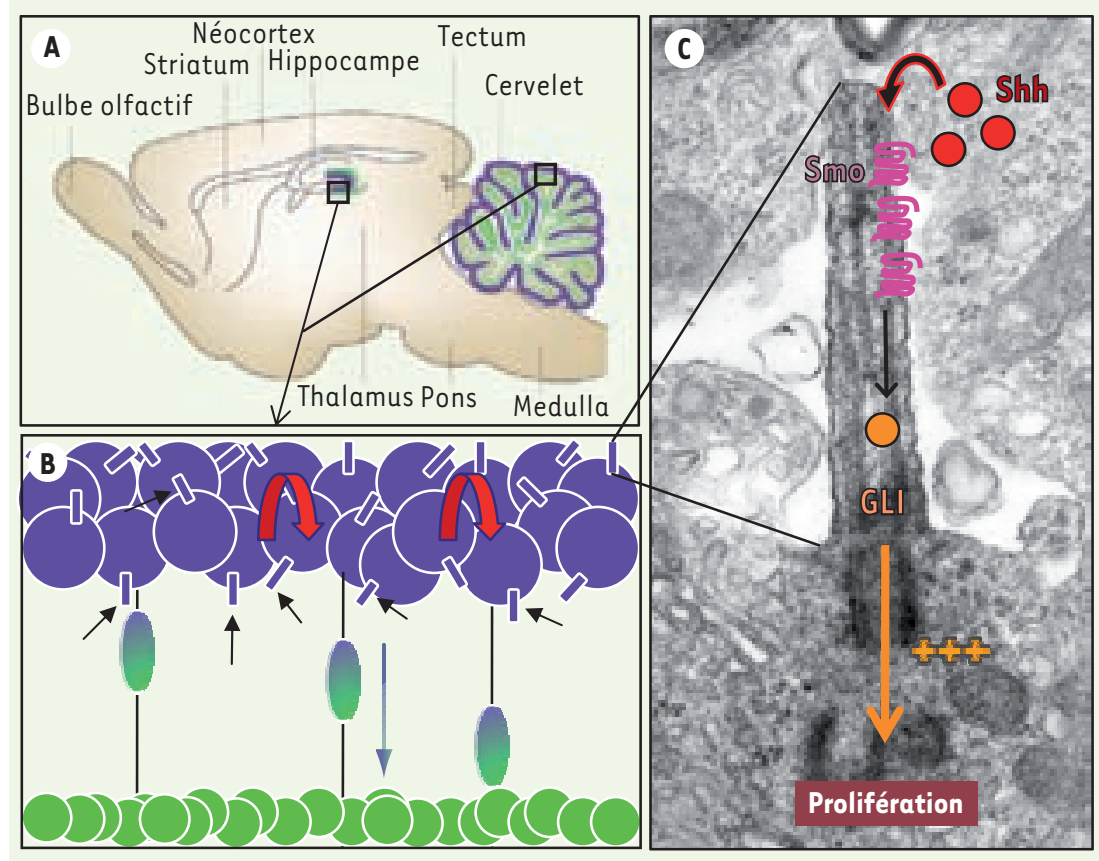

Figure 1. Rôle du cil primaire des progéniteurs granulaires du cervelet et de l'hippocampe. A. Schéma d'une coupe sagittale de cerveau à P2. A : antérieur; D: dorsal; P: postérieur; $V$ : ventral. $\boldsymbol{B}$. Les progéniteurs granulaires du gyrus dentelé de l'hippocampe et du cervelet (couche violette) possèdent un cil primaire (flèche noire). Ils prolifèrent activement en réponse à Shh (flèche rouge), migrent, et se différencient (flèche bicolore) en neurones granulaires (couche verte). C. Photographie en microscopie électronique à transmission du cil primaire servant de base à un schéma de la transmission ciliaire du signal Shh. Le cil primaire concentre Smo, un des récepteurs activé par Shh qui entraîne la régulation de l'expression des protéines Gli. Ces dernières contrôlent ensuite la prolifération des progéniteurs granulaires.

de ces progéniteurs en réponse à Shh (Figure 1). De même, l'inactivation du gène codant pour Smo, le récepteur de Shh dans ces progéniteurs, a pour effet d'inhiber leur prolifération. À l'inverse, l'activation constitutive de la voie Shh par l'expression de SmoM2 (un récepteur constitutivement actif) [8] dans ces progéniteurs provoque une surproduction des neurones granulaires. Comme attendu, nous montrons que ces deux effets sont réduits par la suppression du cil primaire chez les doubles mutants Smo-Kif3a et SmoM2-Kif3a. Le cil primaire est donc bien indispensable à la transduction du signal Shh dans ces progéniteurs.

Enfin, l'étude de deux autres mutants des gènes ciliaires, fantom et polaris, qui présentent des défauts similaires de pro-
Shh regulates neurogenesis through primary cilia

\section{REMERCIEMENTS}

Young-Goo Han et Arturo Alvarez-Buylla qui ont largement contribué au travail résumé dans cet article, ainsi que les membres de notre équipe pour leur soutien et leurs encouragements tout au long de ce travail.

Notre équipe est financée par The International Human Frontier Science Program Organization, l'Agence Nationale pour la Recherche et la Fondation NRJ-Institut de France.

\section{RÉFÉRENCES}

1. Alvarez-Buylla A, Garcia-Verdugo JM, Tramontin AD. A unified hypothesis on the lineage of neural stem cells Nat Rev Neurosci $2001 ; 2: 287-93$.

2. Stecca B, Ruiz i Altaba A. Brain as a paradigm of organ growth : Hedgehog-Gli signaling in neural stem cells and brain tumors. J Neurobiol 2005 ; 64 : 476-90.

3. Singla V, Reiter JF. The primary cilium as the cell's antenna : signaling at a sensory organelle. Science $2006 ; 313: 629-33$

4. Badano JL, Mitsuma N, Beales PL, Katsanis N. The ciliopathies: an emerging class of human genetic disorders. Annu Rev Genomics Hum Genet 2006; 7: 125-48.

5. Davenport JR, Watts AJ, Roper VC, et al. Disruption of intraflagellar transport in adult mice leads to obesity and slow-onset cystic kidney disease. Curr Biol 2007 ; 17 : 1586-94.

6. Han YG, Spassky N, Romaguera-Ros M, et al. Hedgehog signaling and primary cilia are required for the formation of adult neural stem cells. Nat Neurosci $2008 ; 11: 277-84$

7. Spassky N, Han YG, Aguilar A, et al. Primary cilia are required for cerebellar development and Shhdependent expansion of progenitor pool. Dev Biol 2008; 317: 246-59.

8. Mao J, Ligon KL, Rakhlin عy, et al. A novel somatic mouse model to survey tumorigenic potential applied to the Hedgehog pathway. Cancer Res 2006 ; $66: 10171-8$.

9. Chizhikov VV, Davenport J, Zhang (, et al. Cilia proteins control cerebellar morphogenesis by promoting expansion of the granule progenitor pool. J Neurosci $2007: 27: 9780-9$

10. Huangfu D, Liu A, Rakeman AS, et al. Hedgehog signalling in the mouse requires intraflagellar transport proteins. Nature $2003 ; 426: 83-7$.

11. Huangfu D, Anderson KV. Cilia and Hedgehog responsiveness in the mouse. Proc Natl Acad Sci USA 2005 ; 102 : 11325-30.

12. De Chevigny $A$, Lledo PM. La neurogenèse bulbaire et son impact neurologique. Med Sci (Paris) 2006; 22 : 607-13.

13. Dollfus H, Muller J, Stoetzel C. Syndrome de BardetBiedl : une famille unique pour un gène majeur (BBS10). Med Sci (Paris) 2006 ; 22: 901-4.

14. Schüller U, Heine VM, Mao J, et al. Acquisition of granule neuron precursor identity is a critical determinant of progenitor cell competence to form Shh-induced medulloblastoma. Cancer Cell 2008 ; $14: 123-34$. 